\title{
SFC with evaporative light-scattering detection and atmospheric-pressure chemical-ionisation mass spectrometry for methylated glucoses and cyclodextrins analysis
}

\author{
B. Herbreteau, A. Salvador, M. Lafosse and M. Dreux
}

Institut de Chimie Organique et Analytique, UPRES-A CNRS 6005, Université d'Orléans, BP 6759, 45067 Orléans Cedex 02, France

Packed-column supercritical-fluid chromatography (pSFC) with a $\mathrm{CO}_{2}$-polar modifier mobilephase was used for the analysis of methylated glucoses and methylated- $\beta$-cyclodextrins. The interface with evaporative light-scattering detection (ELSD) was studied with regards to the effect of the position of the restrictor capillary (either at the column outlet or at the ELSD interface) and to the influence of the internal diameter of the nebulization capillary both on peak shape and on ELSD response. An unmodified LC interface of ELSD can be successful and it led to an increase in signal-to-noise ratios of methylated glucoses by a factor from 10 to 30 . Likewise, an unmodified LC interface of atmospheric-pressure chemical-ionisation mass spectrometry (APCI-MS) can successfully be used for pSFC-APCI-MS analysis of methylated- $\beta$-cyclodextrin mixtures. pSFC-ELSD is a good and inexpensive approach for pSFC-APCI-MS method development.

Keywords: SFC, Subcritical-fluid chromatography, ELSD, APCI-MS, methylated glucoses, methylated- $\beta$ cyclodextrins

\section{Introduction}

Packed-column supercritical-fluid chromatography (pSFC) and related chromatography (e.g. subcritical-fluid or superheated-water chromatography) have a great deal to offer and are under-utilised techniques [1,2]. Column equilibration and analysis times are shorter than in liquid chromatography (LC). Moreover, separations are often different from and complementary to those obtained in LC [3-8]. pSFC mainly uses LC-like detectors, such as UV, evaporative light-scattering detection (ELSD) [3-10], or atmospheric-pressure ionisation mass-spectrometry (API-MS) [2,9,11-27] including ionspray or electrospray (IS-MS) and atmospheric-pressure chemical-ionisation mass spectrometry (APCI-MS). ELSD and API-MS are low-pressure detectors especially appropriate to non-UV-absorbing analytes. They both require nebulization and vaporization of the mobile phase. For this rea- son, ELSD was proven to be a good and inexpensive approach for method development in LC [28-30]. Transposition of separation methods from LC-ELSD to LCAPI-MS was successful. For pSFC, the transposition is more complex because of the necessity to regulate pressure. APIMS interfaces are commonly modified to incorporate the restrictor at the end of the MS source capillary [9,11-27]. However, in the case of APCI-MS, an unmodified LC interface has recently been introduced for $\mathrm{pSFC}$ with pure- $\mathrm{CO}_{2}$ mobile phase [2].

In the present work, with $\mathrm{CO}_{2}$-modifier mobile-phases, the ELSD interface design was studied with the intention of placing the restrictor at the column outlet inside the oven. Test solutes were methylated glucoses [7] and methylated$\beta$-cyclodextrins $(\mathrm{M} \beta \mathrm{CD})[6,31]$. M $\beta \mathrm{CD}$ are cyclic glucose oligomers methylated in various positions which are difficult to characterize. Once the interface design was optimized, pSFC-ELSD conditions were directly applied to pSFC-APCI-MS to provide structural information on complex M $\beta C D$ mixtures.

\section{Experimental}

SFC analyses were conducted with an SF3 system (Gilson, Villiers-le-Bel, France) including $\mathrm{CO}_{2}$ and modifier pumps, a 7125 injection valve with $20 \mu \mathrm{l}$ sample loop (Rheodyne, Berkeley, CA, USA), and a Croco-Cil ${ }^{\mathrm{TM}}$ column oven (CILCluzeau, Sainte-Foy-la-Grande, France). The columns used were Zorbax Sil, $7 \mu \mathrm{m}, 4.6 \times 150 \mathrm{~mm}$ (Dupont, Wilmington, DE, USA) and Nucleosil $\mathrm{NO}_{2}, 10 \mu \mathrm{m} \times 4.6 \times 150 \mathrm{~mm}$ (Shandon, Cheshire, UK).

The ELSD Sedex 55 (Sedere, Alfortville, France) was used with SFC or LC interface. First experiments were made with the commercial ELSD-SFC interface (Fig. 1a) equipped with a linear restrictor (fused silica, $5 \mathrm{~cm}$ length, $50 \mu \mathrm{m}$ ID). For the study of the interface design, this restrictor was placed inside the oven at the column outlet, and a nebulization capillary (5 cm length; either fused silica, 50, 75 or $100 \mu \mathrm{m}$ ID; or PEEK, 130 or $180 \mu \mathrm{m}$ ID) was used as the SFC interface (Fig. 1b). A PEEK tubing (75 cm length, 130 $\mu \mathrm{m}$ ID) was used as the transfer line between the restrictor in the oven and the nebulization capillary in the ELSD. An 
a

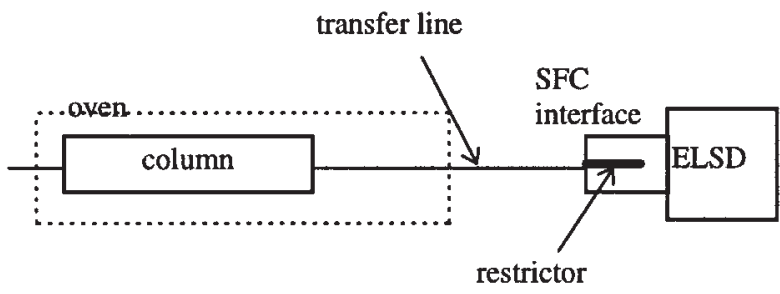

b

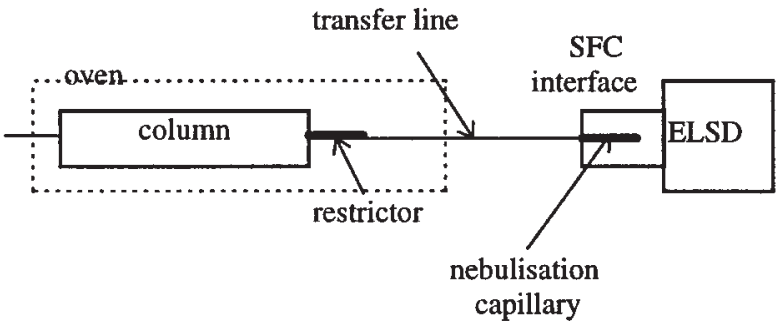

$\mathrm{C}$

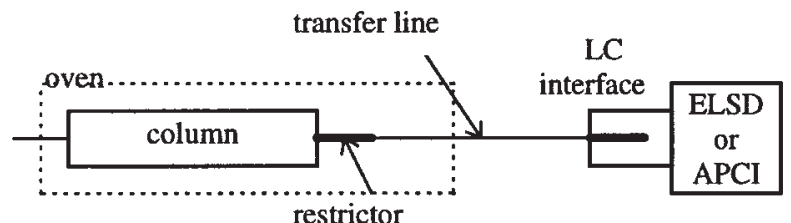

Figure 1. Schematic diagrams of various configurations used for restriction and nebulization a) commercial SFC-ELSD interface, b) restrictor and various nebulization capillaries as the SFCELSD interface, c) unmodified LC interface for ELSD or APClMS.

LC-ELSD interface consisting of the standard nebulization needle (400 $\mu \mathrm{m}$ ID) was also implemented, the transfer line being directly connected to this interface (Fig. 1c). The ELSD setting was as follows: photomultiplier, 7; evaporative temperature, $50{ }^{\circ} \mathrm{C}$; air pressure, 0.5 bar for the $\mathrm{SFC}$ interface and 1 bar for the LC interface; nebulizer temperature (only with the SFC interface), $50{ }^{\circ} \mathrm{C}$. Data were processed using a CR 5A integrator (Shimadzu, Kyoto, Japan).

For SFC-APCI-MS, the transfer line was directly connected to the standard LC-APCI source of the API 300 mass spectrometer (Perkin-Elmer, Thornhill, Ontario, Canada) (Fig. 1c). The APCI-MS setting was: quartz tube temperature, $400{ }^{\circ} \mathrm{C}$; corona, $3 \mu \mathrm{A}$; nebulization gas, 3 bar; auxiliary gas, 10; curtain gas, 9; ring, $300 \mathrm{~V}$; orifice, $50 \mathrm{~V}$; scan for $\mathrm{m} / \mathrm{z}$ from 1100 to 1700 in positive mode.

Carbon dioxide was of industrial grade, $99.7 \%$ purity (Air Liquide, Paris, France). Methanol (Mallinckrodt Baker, Noisy-le-Sec, France) and triethylamine (Chromanorm, Paris, France) were of analytical grade. Water was distilled and filtered through an UHQ purification system (Elga, High Wycombe Bucks, England). D-Glucose (RP Normapur, Prolabo, Paris, France) and 3-O-methyl-D-glucopyranose (Sigma, Saint Louis, MO, USA) were used. 2,3,6-tri- $O$ methyl-D-glucopyranose and 2,6-di- $O$-methyl-D-glucopyranose were obtained from hydrolysis of heptakis $(2,3,6$-tri- $O$-methyl)- $\beta$-cyclodextrin and heptakis $(2,6$-di- $O$ methyl)- $\beta$-cyclodextrin respectively [7]. These four solutes were dissolved in methanol at the $500 \mathrm{mg}^{-\mathrm{l}^{-1}}$ concentration for each solute. By successive dilution of this mother solution in methanol, the following three concentrations were

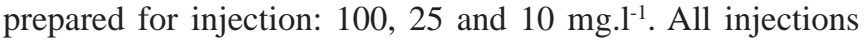
and quantitations were made in triplicate. Commercial methylated- $\beta$-cyclodextrin mixtures were dissolved in methanol before injection.

No differentiation will be made between SFC and what is sometimes called subcritical-fluid chromatography because the transitions between the so-defined states are chromatographically undetectable and the implemented instrumentation is identical.

\section{Results and discussion}

pSFC-ELSD was studied using $\mathrm{CO}_{2}$-modifier mobile phases. Optimization of the chromatographic conditions was described elsewhere for methylated glucoses [7] and M $\beta C D$ [31].

\section{SFC-ELSD analysis of methylated glucoses}

In previous works from the author's laboratory [3-8,10,31], the SFC interface equipped with a linear restrictor (fused silica, $5 \mathrm{~cm}$ length, $50 \mu \mathrm{m}$ ID) was used. In this case, the capillary simultaneously acts as a restrictor and as a nebulization capillary. With a view to achieving SFC-APCI-MS with an unmodified LC interface, the same restrictor was used but it was placed inside the oven at the column outlet (figure 1b). A nebulization capillary had to be added in the SFC interface of ELSD. Consequently, partial decompression of mobile phase occurred in the transfer line. The influence of the restrictor capillary position on peak shape was studied. Figures $2 \mathrm{a}$ and $2 \mathrm{~b}$ show that, in the conditions used, peak shapes of methylated glucoses were not affected by the restrictor position. However, if mass transfer problems occur for low solubility compounds (e.g. polyethoxylated alcohols), a make-up solvent can be added at the column outlet using an additional LC pump [10, 32]. Alternatively, a pressure-regulating fluid interface can be used [9].

The ELSD response was higher with the restrictor at the column outlet (Fig. 2b) than with the restrictor at the SFC interface (Fig. 2a). Consequently, the influence of the internal diameter of the nebulization capillary was studied. The larger the diameter of the nebulization capillary, the higher the ELSD response. Therefore, the LC interface of ELSD (including $400 \mu \mathrm{m}$ ID needle) was also used (Fig. 2c). The detection limit was less than $10 \mathrm{ng}$ injected (Fig. 2d). 


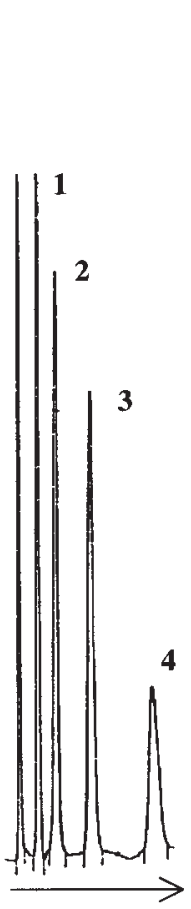

a

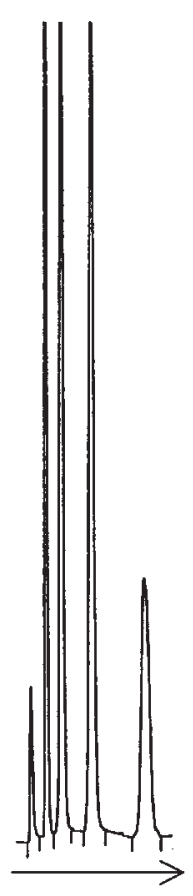

b

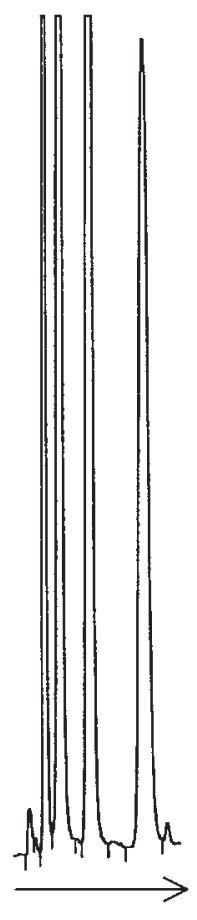

$\mathrm{c}$

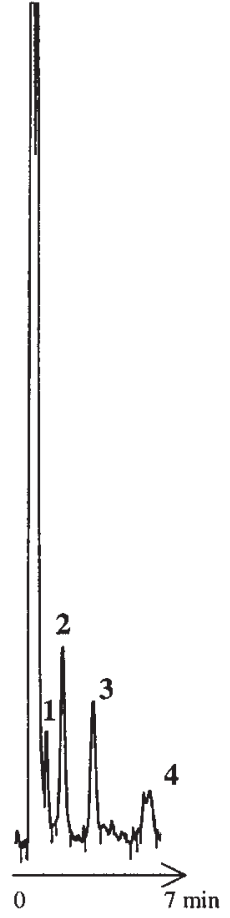

d
Figure 2. pSFC-ELSD of $100 \mathrm{mg.l^{-1 }}(\mathrm{a}, \mathrm{b}, \mathrm{c})$ or $0.5 \mathrm{mg} . \mathrm{l}^{-1}(\mathrm{~d})$ methylated glucoses using SFC interface $(a, b)$ or LC interface $(c, d)$. Configuration as in figure $1 a$ for $a$, as in figure $1 b$ for $b$, as in figure 1c for cand d. Nebulization capillary in b was $5 \mathrm{~cm}$ length, $100-\mu \mathrm{m}$ ID fused silica. Column : Zorbax Sil at $41^{\circ} \mathrm{C}$. Mobile phase: $\mathrm{CO}_{2} /$ methanol/water/triethylamine $(\mathrm{v} / \mathrm{v} / \mathrm{v} / \mathrm{v}$ 85/14.25/0.75/0.075) at $15 \mathrm{MPa}$ and $4 \mathrm{ml}^{\mathrm{min}} \mathrm{m}^{-1}$. Solutes: $1=$ trimethyl glucose, 2 = dimethyl glucose, 3 = monomethyl glucose, 4 = glucose.

Since the noise amplitude was approximately constant, the signal-to-noise ratio $(\mathrm{S} / \mathrm{N})$ increased as a function of the nebulization capillary ID, both for the SFC and the LC interfaces (Fig. 3). It was approximately increased by a factor from 10 to 30 when a standard SFC interface $(50 \mu \mathrm{m}$ capillary ID) is replaced by the LC interface. Calibration curves, from 10 to $500 \mathrm{mg} . \mathrm{l}^{-1}$, were made for the various nebulization conditions (Tab. I). Clearly, the slope decreases and the intercept increases when the nebulization capillary ID increases. This is due to variations in the aerosol production [10]. Particle size probably increases as a function of the capillary ID, and particle size distribution may be quite different from one capillary to another. This affects the lightscattering mechanisms [10]. More studies have to be made in order to interpret these results more precisely. When the nebulization capillary ID increases, the slopes of calibration curves, as well as the intercepts, become very close for the four analytes (Tab. I). Consequently, the ELSD response becomes independent of the methylation degree of these

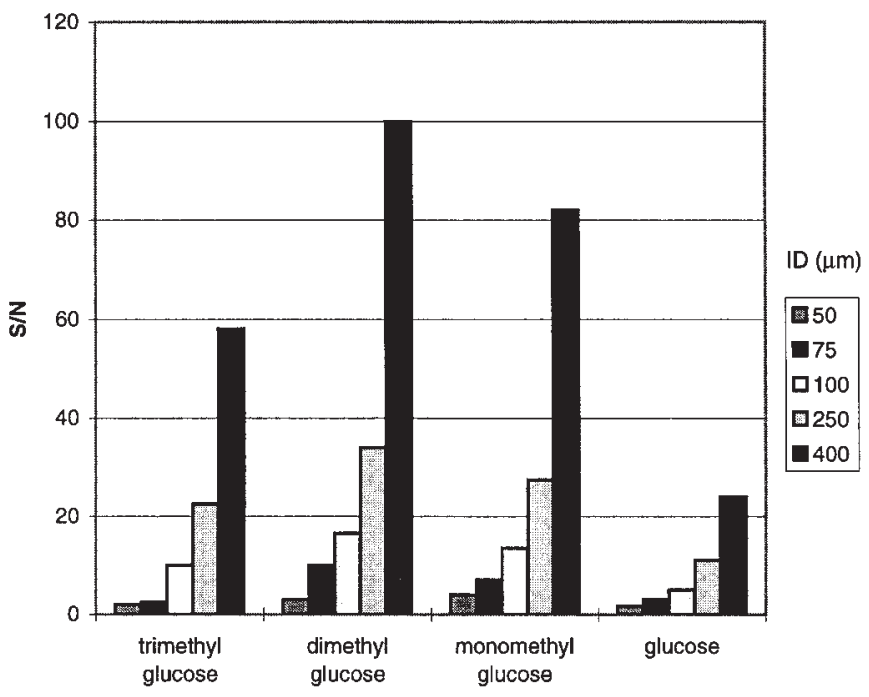

Figure 3. Signal-to-noise ratio $(\mathrm{S} / \mathrm{N})$ as a function of the nebulization capillary ID using SFC interface (from 50 to $250 \mu \mathrm{m}$ ID) and LC interface (400 $\mu \mathrm{m}$ ID) of ELSD. Other conditions as in figure $2 b$ and $c$.

analytes, and it may be concluded that calibration is no longer necessary for the area-normalization quantitation of methylated glucose mixtures.

\section{SFC-ELSD and SFC-APCI-MS analysis of $M \beta C D$ mixtures}

For M $\beta C D$ mixtures analysis using SFC-ELSD, the influence of restrictor position and nebulization capillary ID is similar to that obtained with methylated glucoses (Fig. 4). Clearly, the chromatographic profile was not affected by the restrictor position. The use of a large nebulization capillary or an LC interface is also a good choice (Fig. 5). Lower concentrations can be used.

Since $\mathrm{M} \beta C D$ are complex mixtures, MS is a method of choice for sample characterization. Previously, samples were characterized by performing off-line electrospray-MS of some collected fractions [31]. This was time consuming and, from this point of view, SFC-APCI-MS is more attractive. We found that analytical conditions optimized for pSFCELSD can directly be transposed to pSFC-APCI-MS. By placing the restrictor at the column outlet, it was possible to use the unmodified LC-APCI interface (Fig. 6) as well as the LC-ELSD interface. Only APCI parameters which affect the ionisation process have to be optimized (Fig. 7). The limit of detection, estimated for pure trimethylated- $\beta$ cyclodextrin (2.0 min retention time), was less than $0.1 \mathrm{ng}$ injected.

Protonated molecules were mainly observed in the APCI spectra (Fig. 8a) but $\left[\mathrm{M}+\mathrm{NH}_{4}\right]^{+}$and $[\mathrm{M}+\mathrm{H}+\mathrm{MeOH}]^{+}$were also found. Reconstructed chromatograms using protonated 
Table I. Slope and intercept of ELSD calibration curves for methylated glucoses using various nebulization capillary in SFC interface (from 50 to $400 \mu \mathrm{m}$ ID) and LC interface (400 $\mu \mathrm{m}$ ID). Calibration curves were made in log-log coordinates [10] using log area $=$ slope (log concentration) + intercept.

\begin{tabular}{lcccccccccc}
\hline $\begin{array}{l}\text { Nebulization } \\
\text { capillary ID }(\mu \mathrm{m})\end{array}$ & 50 & 75 & $\begin{array}{c}\text { Slope } \\
100\end{array}$ & 250 & 400 & 50 & 75 & 100 & 250 & 400 \\
\hline Trimethyl glucose & 2.33 & 2.11 & 1.71 & 1.51 & 1.36 & 0.14 & 2.91 & 5.59 & 6.68 & 8.17 \\
Dimethyl glucose & 1.70 & 1.63 & 1.59 & 1.36 & 1.21 & 3.68 & 5.76 & 6.56 & 7.92 & 9.40 \\
Monomethyl glucose & 1.75 & 1.65 & 1.57 & 1.40 & 1.25 & 3.43 & 5.69 & 6.73 & 7.74 & 9.22 \\
Glucose & 1.94 & 1.72 & 1.68 & 1.48 & 1.32 & 1.79 & 4.63 & 5.68 & 7.02 & 8.55 \\
\hline
\end{tabular}
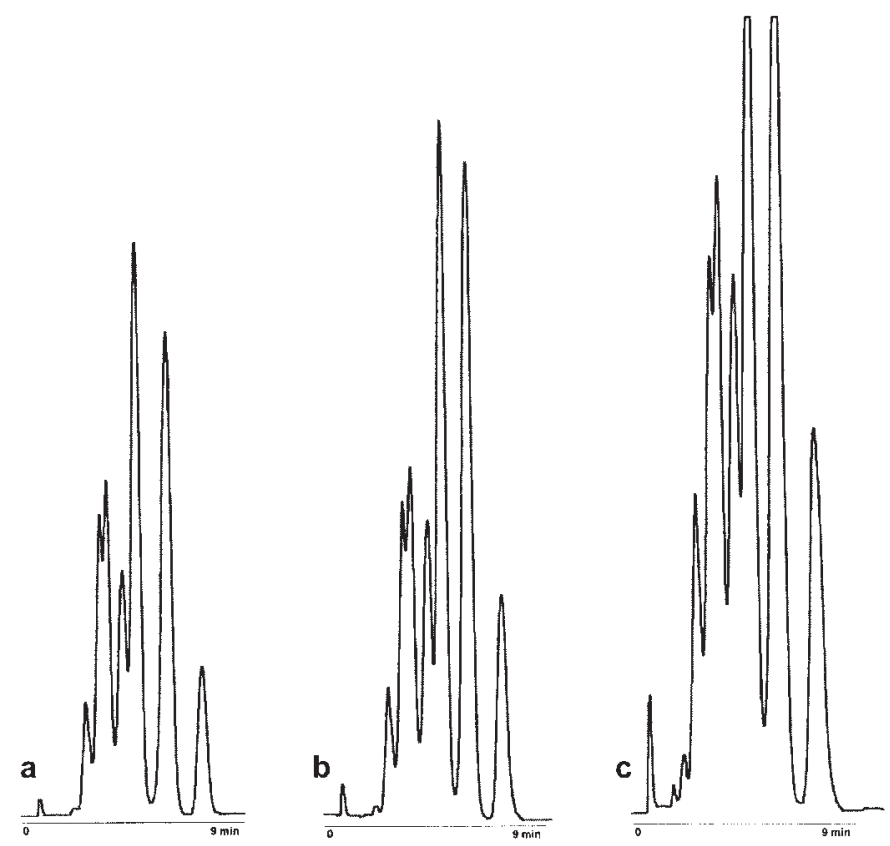

Figure 4. pSFC-ELSD of $1000 \mathrm{mg} . \mathrm{l}^{-1}$ commercial methylated- $\beta$ cyclodextrin mixture using SFC interface as in figure $1 \mathrm{~b}$. Nebulization capillary was 75 (a), 100 (b) and 130 (c) $\mu \mathrm{m}$ ID. Column: Nucleosil $\mathrm{NO}_{2}$ at $41{ }^{\circ} \mathrm{C}$. Mobile phase: $\mathrm{CO}_{2} /$ methanol (v/v 86/14) at $15 \mathrm{MPa}$ and $3 \mathrm{ml} \cdot \mathrm{min}^{-1}$.

molecules $\mathrm{m} / \mathrm{z}$ (Fig. 6) allowed the identification of the $\mathrm{M} \beta \mathrm{CD}$ as a function of the number of methyl groups per molecule. The results were in accordance with those obtained with collected-fraction SFC and off-line IS-MS [31], but minor peaks were identified in the present work (e.g. peaks 10 and 11, Fig. 6). It can also be noted that positional isomers of $M \beta C D$, having the same $\mathrm{m} / \mathrm{z}$, exist in the mixture (e.g. two peaks for 16,17 and 18 methyl- $\beta-C D$ ).

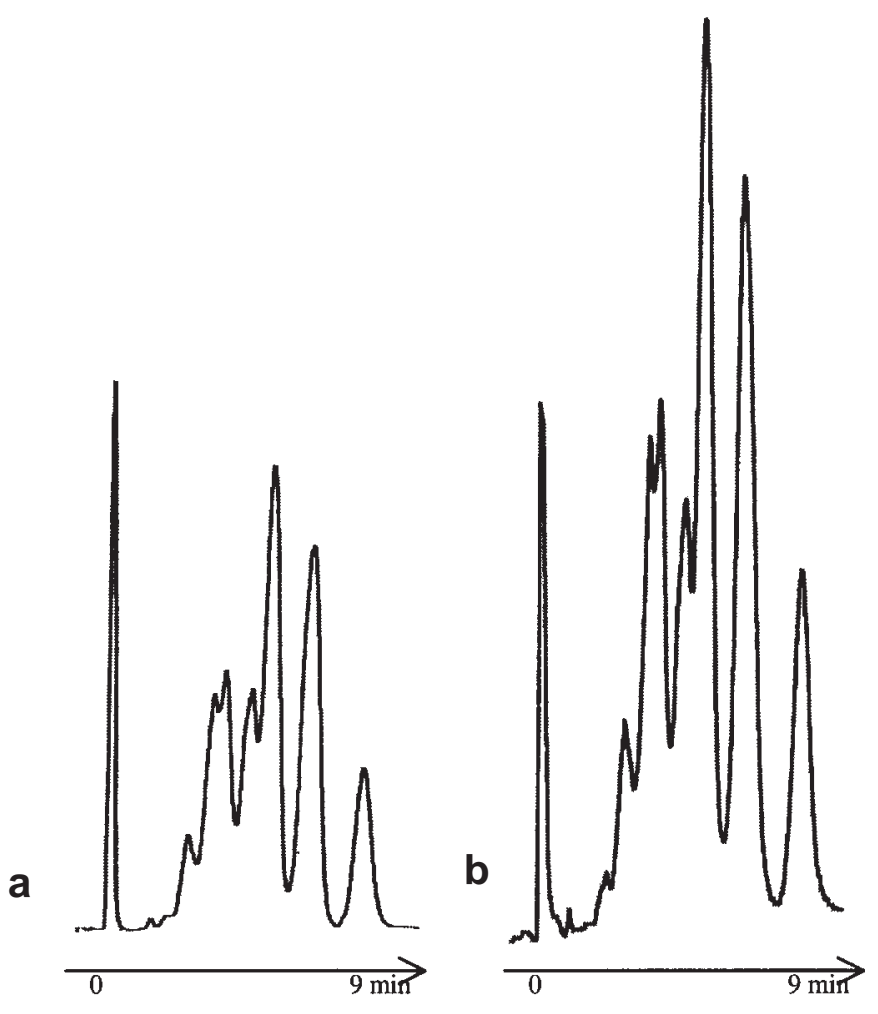

Figure 5. pSFC-ELSD of $100 \mathrm{mg} . \mathrm{l}^{-1}$ commercial methylated- $\beta$ cyclodextrin mixture using SFC interface as in figure $1 \mathrm{~b}(\mathrm{a})$, and using LC interface as in figure 1c (b). Restrictor was placed inside the oven at the column outlet. Nebulization capillary in a was $130 \mu \mathrm{m}$ ID. Other conditions as in figure 4 .

Fragmentation occurred in the APCI interface, due to a sequential loss of methylated glucose units (e.g. loss of dimethyl units, MW 190, Fig. 8a). Similar results were obtained with IS-MS-MS [31]. Both IS-MS-MS and APCIMS can distinguish symmetrical 14 methyl- $\beta-C D$ 


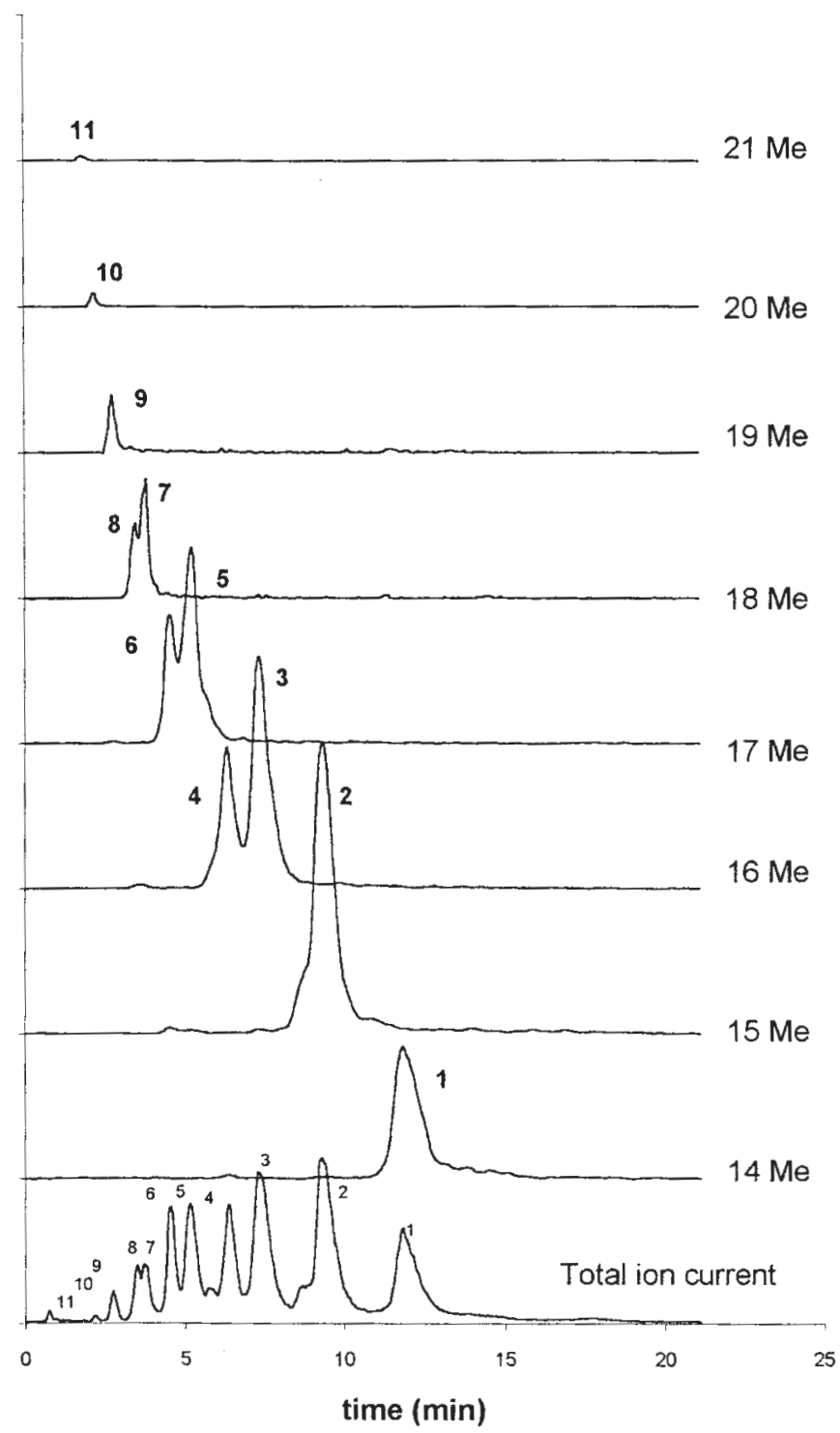

Figure 6. pSFC-APCl-MS of $1000 \mathrm{mg.l}^{-1}$ commercial methylated$\beta$-cyclodextrin mixture using unmodified LC-APCI interface as in figure 1c. Reconstructed ion chromatograms after ion extraction of protonated molecules show that from 14 to 21 methyl groups per molecule were found. Column: Nucleosil $\mathrm{NO}_{2}$ at $41^{\circ} \mathrm{C}$. Mobile phase: $\mathrm{CO}_{2} /$ methanol (v/v 88/12) at $15 \mathrm{MPa}$ and $3 \mathrm{ml} \cdot \mathrm{min}^{-1}$.

(seven 2,6 dimethyl glucose units, Fig. 8a) and asymmetrical 14 methyl- $\beta-C D$ (one trimethyl unit, five 2,6 dimethyl units and one monomethyl unit, Fig. 8b). For asymmetrical $\mathrm{M} \beta \mathrm{CD}$, various fragmentation series can be found and positional isomers are numerous. Complete interpretation of spectra is not possible.

SFC-APCI-MS of complex samples is shown in Fig. 9. Clearly, the complexity of sample b is very high and only a characteristic fingerprint is obtained. Sample a contains symmetrical and asymmetrical 14 methyl- $\beta-C D$. Better characterization of $\mathrm{M} \beta \mathrm{CD}$ mixtures is obtained with $\mathrm{pSFC}$ APCI-MS as compared with pSFC-ELSD. This is crucial because complexation constants of $\mathrm{M} \beta \mathrm{CD}$ are dependent on the position of methyl groups around the cyclodextrins [33].

\section{Conclusions}

In pSFC with $\mathrm{CO}_{2}$-modifier mobile phase, the restrictor can be placed inside the oven at the column outlet without any mass transfer problems. This allows the use of ELSD, as well as APCI-MS, unmodified LC interfaces with flow rates up to $3 \mathrm{ml} \cdot \mathrm{min}^{-1}$. For the tested solutes, LC interface of ELSD was proven to be superior to SFC interface in terms of $\mathrm{S} / \mathrm{N}$ ratio which can be increased by a factor from 10 to 30. In addition, pSFC-ELSD was a good and inexpensive approach for pSFC-APCI-MS method development. After pSFC-ELSD optimization, precious information can be rapidly available using pSFC-APCI-MS.

\section{Ackowledgments}

Thanks are due to Francis Vérillon for fruitful discussions. This work was supported by the Conseil Régional de la Région Centre (France).

\section{References}

1. Chester, T.; Pinkston, J.; Raynie, D. Anal. Chem. 1998, 70, 301R-319R.

2. Morgan, D.; Harbol, K.; Kitrinos, N. J. Chromatogr. A 1998 , 800, 39-49.

3. Herbreteau, B.; Lafosse, M.; Morin-Allory, L.; Dreux, M. J. Chromatogr. 1990, 505, 299-305.

4. Morin-Allory, L.; Herbreteau, B. J. Chromatogr. 1992, 590, 203-213.

5. Herbreteau, B.; Lafosse, M.; Dreux, M.; Krzych, V.; André, P. IJBC. 1996, 1, 301-307.

6. Caron, I.; Salvador, A.; Elfakir, C.; Herbreteau, B.; Dreux, M. J. Chromatogr. A 1996, 746, 103-108.

7. Salvador, A.; Herbreteau, B.; Lafosse, M.; Dreux, M. Analusis 1997, 25, 263-266.

8. Salvador, A.; Herbreteau, B.; Lafosse, M.; Dreux, M. J. Chromatogr. A 1997, 785, 195-204.

9. Chester, T.; Pinkston, J. J. Chromatogr. A 1998, 807, 265-273.

10. Lafosse, M. in Practical Supercritical Fluid Chromatography and Extraction; Caude, M. and Thiébaut, D., Ed.; Harwood Academic Publishers: Amsterdam, 1999; pp 201-218.

11. Anacleto, J. F.; Ramaley, L.; Boyd, R. K.; Pleasance, S.; Quilliam, M. A.; Sim, P. G.; Benoit, F. M.; Rapid. Commun. Mass Spectrom. 1991, 5, 149-155. 

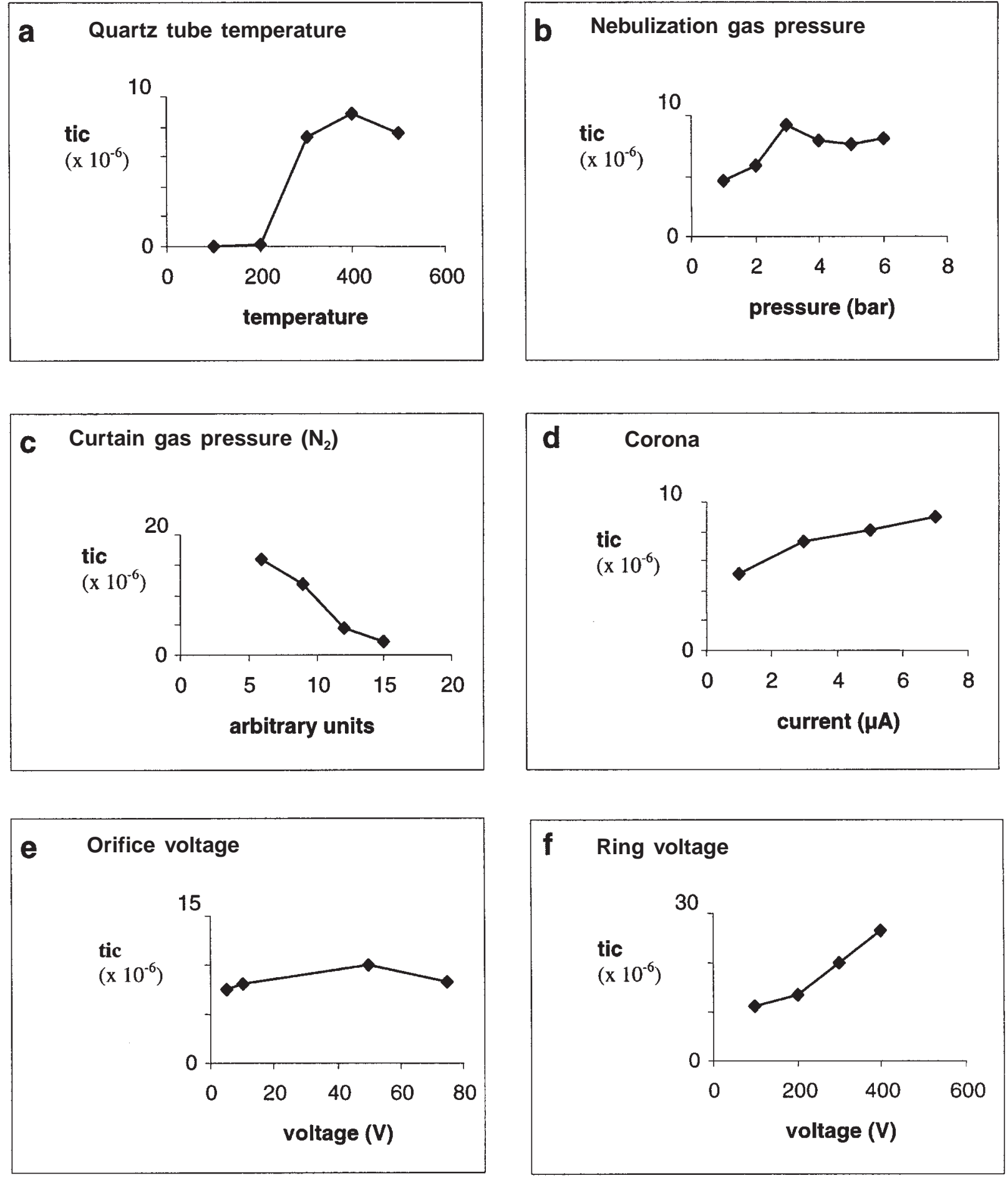

Figure 7. APCI parameter optimization for methylated- $\beta$-cyclodextrins detection. Chromatographic conditions as in figure 6 . Default $\mathrm{APCl}$ parameters used: quartz tube temperature, $400^{\circ} \mathrm{C}$; corona, $3 \mu \mathrm{A}$; nebulization gas, $0.3 \mathrm{MPa}$; auxiliary gas, 10 ; curtain gas, 9 ; ring, $300 \mathrm{~V}$; orifice, $50 \mathrm{~V}$. 
a

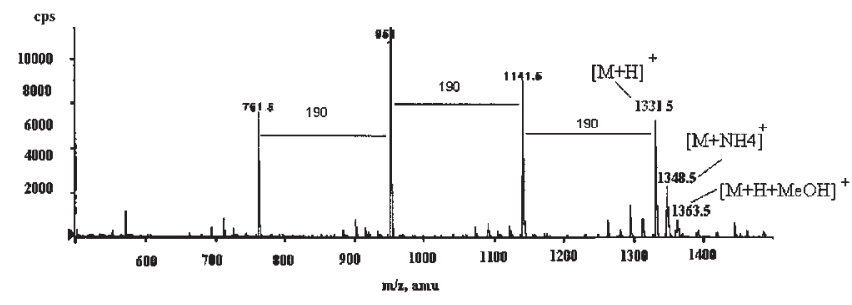

b

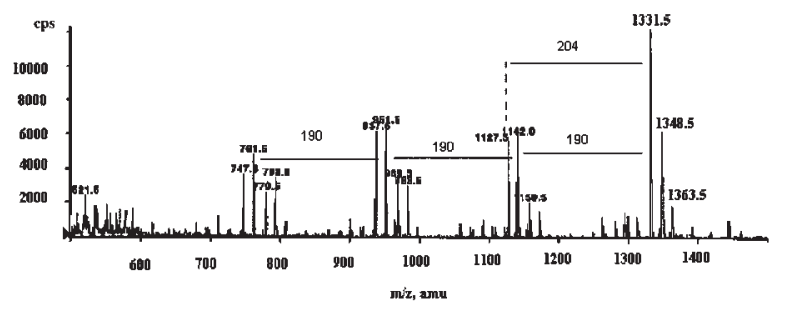

Figure 8. APCI spectra from a symmetrical (a) and an asymmetrical (b) 14 methyl $\beta$-cyclodextrin obtained from the two $14 \mathrm{Me}$ peaks of figure $9 a$.

12. Matsumoto, K.; Nagata, S.; Hattori, H.; Tsuge, S. J. Chromatogr. 1992, 605, 87-94.

13. Arpino, P.; Sadoun, F.; Virezelier, H. Chromatographia 1993, 36, 283-288.

14. Sadoun, F.; Virezelier, H.; Arpino, P. J. Chromatogr. 1993, 647, 351-359.

15. Tyrefors, L.; Moulder, R.; Markides, K. Anal. Chem. 1993, 65, 2835-2840.

16. Pinkston, J.D.; Baker, T.R. Rapid Commun. Mass Spectrom. 1995, 9, 1087-1094.

17. Lazar, I.; Lee, M. L.; Lee, E.D. Anal. Chem. 1996, 68, 19241932.

18. Schmeer, K.; Nicholson, G.; Zhang, S.; Bayer, E.; BohningGaese, K. J. Chromatogr. A 1996, 727, 139-146.

19. Broadbent, J.; Martincigh, B.; Raynor, M.; Salter, L.; Moulder, R.; Sjöberg, P.; Markides, K. J. Chromatogr. A 1996, 732, 101-110.

20. Manninen, P.; Laakso, P. Lipids. 1997, 32, 825-831.

21. Moyano, E.; McCullagh, M.; Galceran, M.T.; Games, D.E. J. Chromatogr. A 1997, 777, 167-176.

22. Bäckström, B.; Cole, M.D.; Carrott, M.J.; Jones, D.C.; Davidson, G.; Coleman, K. Science \& Justice 1997, 37(2), 9197.

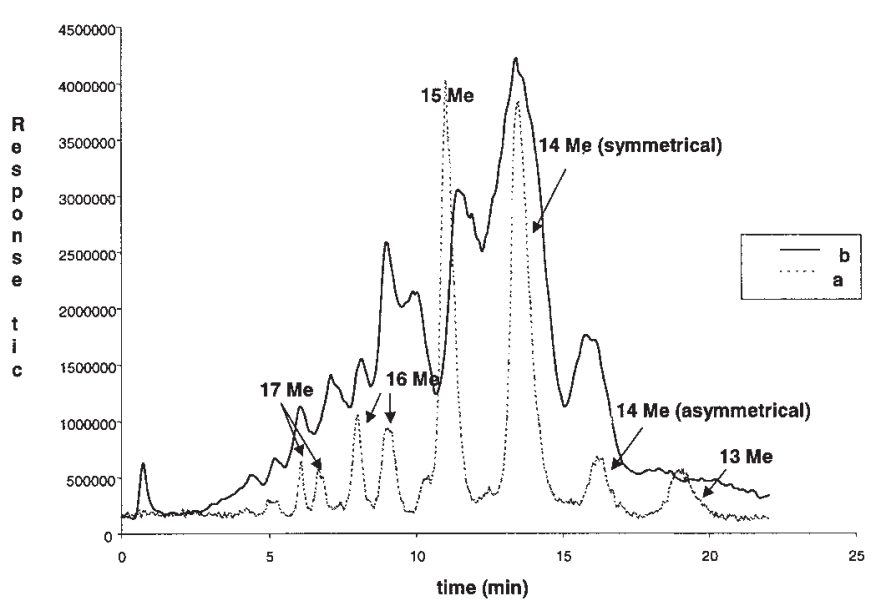

Figure 9. pSFC-APCI-MS of two complex methylated- $\beta$-cyclodextrin mixtures (a and b). Conditions as in figure 6 .
23. Ramsey, E.; Minty, B.; McCullagh, M.; Games, D.; Rees, A. Anal. commun. 1997, 34, 3-6.

24. Sjöberg, Per J. R.; Markides, K. E. J. Chromatogr. A 1997, 785, 101-110.

25. Combs, M.; Ashraf-Khorassani, M.; Taylor, L. J. Chromatogr. A 1997, 785, 85-100.

26. Baker, T.; Pinkston, J. J. Am. Soc. Mass Spectrom. 1998, 9, 498-509.

27. Pinkston, J. in Practical Supercritical Fluid Chromatography and Extraction; Caude, M. and Thiébaut, D., Ed.; Harwood Academic Publishers: Amsterdam, 1999; pp 161-178.

28. Rehbock, B.; Gansser, D.; Berger, R. Lipids 1997, 32, 10031010.

29. Mercier, J-P.; Chaimbault, P.; Salvador, A.; Dreux, M. Poster at HPLC '98, May 1998, Saint Louis, USA.

30. Salvador, A.; Mercier, J-P.; Chaimbault, P.; Dreux, M. Poster at the 46th ASMS Conference on Mass Spectrometry and Related Topics, June 1998, Orlando, USA.

31. Salvador, A.; Herbreteau, B.; Dreux, M. J. Chromatogr. A 1999, 855, 645-656.

32. Brossard, S.; Lafosse, M.; Dreux, M. J. Chromatogr. 1992, 591, 149-157.

33. Salvador, A.; Varesio, E.; Veuthey, J-L.; Dreux, M. Electrophoresis, in press. 